\title{
Community radio stations sustainability model: An open-source solution
}
Rute Correia, Instituto Universitário de Lisboa (ISCTE-IUL), Centro de Investigação e Estudos de Sociologia (CIES-IUL), Lisboa, Portugal
Jorge Vieira, Instituto Universitário de Lisboa (ISCTE-IUL), Centro de Investigação e Estudos de Sociologia (CIES-IUL), Lisboa, Portugal
Manuela Aparicio, Instituto Universitário de Lisboa (ISCTE-IUL) ISTAR-IUL NOVA Information Management School (Nova IMS), Universidade Nova de Lisboa, Portugal

This is the Accepted Author Manuscript of the article published by Ingenta Radio Journal: International Studies in Broadcast \& Audio Media:

Correia, R., Vieira, J., \& Aparicio, M. (2019). Community radio stations sustainability model: An open-source solution. Radio Journal, 17(1), 29-45.

https://doi.org/10.1386/rjao.17.1.29_1

\section{(c) (1) (9)}

This work is licensed under a Creative Commons Attribution-NonCommercial 4.0 International License. 


\title{
Community radio stations sustainability model: An open-source solution
}

Rute Correia, Instituto Universitário de Lisboa (ISCTE-IUL), Centro de Investigação e Estudos de Sociologia (CIES-IUL), Lisboa, Portugal

Jorge Vieira, Instituto Universitário de Lisboa (ISCTE-IUL), Centro de Investigação e Estudos de Sociologia (CIES-IUL), Lisboa, Portugal

Manuela Aparicio, Instituto Universitário de Lisboa (ISCTE-IUL) ISTAR-IUL

NOVA Information Management School (Nova IMS), Universidade Nova de Lisboa, Portugal

\begin{abstract}
Community radio stations are important social-inclusion structures, empowering communities through media access and production, reinforcing their ties with the wider civil society. The free and open-source software movement has been established since the $1980 \mathrm{~s}$, founded on the freedom to use, to study, to share and to improve a software's source code. It focuses on sharing knowledge, enabling action within a community towards a common goal. With millions of projects and market dominance in specific areas of IT, open source is one of the most successful community movements of our time. In this article, we argue that theoretical frameworks and other insights drawn from the open-source movement can be valuable tools for understanding and critically analysing the designated community radio sphere in terms of technology, content creation and community management to provide a sustainable broadcast practice, expanding already-existing inclusive environments and potentiating empowerment through participation.
\end{abstract}

\section{Keywords}

community radio; open source; copyleft; technology; community; participation

\section{Please cite this article as:}

Correia, R., Vieira, J., \& Aparicio, M. (2019). Community radio stations sustainability model: An open-source solution. Radio Journal: International Studies in Broadcast \& Audio Media, 17(1), 2945. DOI: https://doi.org/10.1386/rjao.17.1.29_1 


\section{Introduction}

Radio broadcasting has been a companion to millions of people all over the world; it is estimated that people listen to the radio on average three hours a day (Deiss 2002). Its importance has crossed borders to reach and serve various information needs, providing value even in the digital age of broadcast radio stations (Lax et al. 2008).

Research on community radio has mainly been focused on its impact in terms of social development within its internal and external communities (meaning producers and listeners) and its relationship with technology. While some exist, there is a lack of academic studies on the sustainability of such structures, not to mention a broad view on why and how they can subsist through time as participatory and inclusive social organizations. The latter has been addressed by practitioners in handbooks and toolkits focused on issues related to everyday radio operation and broadcast (Fogg et al. 2005; Fraser and Estrada 2001). By focusing on the technicalities of everyday operation, which can differ greatly from station to station, these texts fail to provide a deeper reflection of this subject.

Despite the different legal frameworks under which community radio stations operate around the world, they often face similar challenges in terms of their sustainability, namely for the creation of content compliant with copyright regulations, the usage and maintenance of technological means that support the broadcast and the necessary community management skills and knowledge. Fuelled by the hard work and enthusiasm of volunteers, community radio stations reflect a diverse mix of cultures and interests and provide a rich blend of mostly locally produced content. They are an important tool of social inclusion, where participation is at the core of their practice. However, as their activity is not-for-profit, they face specific challenges in keeping their operation sustainable on a long-term basis. These challenges fall into two main categories: financial and labour force (Hussain and Tongia 2007; Jallov 2001). As financial support is often limited, utilizing open-source technology and content should help communities to maximize creative output while minimizing costs. In the long run, since both offer the possibility of product modification by the end user, open-source technology and content have the potential to give community radio stations the tools that they need to remain active. On an organizational level, by enabling a participatory structure, the adoption of an opensource ideology, with a heavy focus on community-based governance models, should increase the level of engagement of the members in the community, which is crucial for the operation of these stations. In her work for UNESCO's Media Development Project in Mozambique, Jallov has also detailed how a 'technical sustainability system' was crucial to the establishment of community radio in the country, feeding the hypothesis that a model that significantly incorporates such a dimension can represent a valuable route for these structures (2001: 12). 
Ultimately, we aim to answer the following question: how can open source be used by community radio stations as a model for their sustainable development in terms of content, technology and communities?

For this initial step, the methodology used was mainly qualitative as we looked at the literature in both community radio and open source. The segmentation of the study across three main areas content, technology and community - is warranted by the fact that they are each fundamental points in both research and practice. Kubitschko and Kaun (2016) advanced a similar approach when focusing on innovative methods of research in media and communication as they explore materiality (in this case, named content), technology and experience (here materialized as communities) (Kubitschko and Kaun 2016).

First, we explore some theoretical background on community radio and on open source, examining each object's history and highlighting some of the key topics of research in each area. Then, we start building the connections between them, outlining and developing the most generic similarities and subsequently examining each axis separately, integrating some empirical findings. Finally, we summarize the findings, opening up ways to further research.

\section{Theoretical background on community radio: Between radio and alternative media}

Community radio has been making waves in academia at least since the 1970s (Lewis and Booth 1989), but its various forms, nomenclature and discourses are deeply dependent on historical contexts and subsequently associated social identities. The term community radio denotes an AngloSaxon tradition and was coined differently in other places, such as France or Germany, where similar structures were named 'radio libre' or 'freie radio' (meaning free radio; free as in freedom) as a result of their usage by activist groups and political resistance movements (Lewis and Booth 1989; Raboy 1993; Scifo 2015: 87). These two terms - community radio and free radio - are prevalent in western literature, with community radio gaining traction in more recent decades.

This pervasiveness of the term in academia can be explained by the growing dominance of English as the most widely used language in science publishing, by the continuous research of community radio in and by English-speaking countries, such as the United Kingdom, Australia and South Africa, and by the decrease in resistance and struggle movements in western Europe with the establishment of the European Union and the subsequent political stability in the larger centres of radio production and development, such as France, Germany and Italy. There is, however, a plethora of other terms that can mean, at least, versions of what we perceive when we think about community radio, such as mini and micro FM (i.e. Japan and United States), popular radio (South American countries), local radio (Scandinavian countries), among others (King 2017; Kogawa 1993; Lewis and 
Booth 1989; Raboy 1993; Scifo 2015). This happens mainly because the social, political, cultural and historical contexts that potentiated such existence were also vastly different.

In the United Kingdom, for instance, the movement started because of the failure of the local radio model developed between the 1960s and the 1980s. Paraphrasing Lewis and Booth, local stations aimed to replicate the national ones, delivering local content in the exact same format (1989: 105), failing to ignite the spark of community within its local audience. The struggle towards legalization comprises a long list of illegal and/or short-term broadcasting adventures, one that includes ship-based pirate stations in the 1960s (like the infamous Radio Caroline), various activistfocused stations (such as Bristolian Fem FM and other women-run organizations) and culturally challenging black music stations (such as Dread Broadcasting Corporation and Radio Invicta, playing reggae and soul music, respectively, filling the gaps left empty by the British Broadcasting Corporation, which catered predominantly to white audiences at the time) (Coyer et al. 2011; Lewis and Booth 1989). Under more dramatic circumstances, grassroots radio played crucial roles in events such as the decolonization movement in Algeria and the Cuban revolution - with Che Guevara even setting up one of the stations, Radio Rebelde, in February 1958 (Raboy 1993). Ultimately, as Scifo clarifies, there are three main features that we find in any of the taxonomies listed: such stations run on a not-for-profit basis, they focus their outreach on a specific community and they exhibit a high level of engagement of the community that they cater for in the running of the station (2015).

To look beyond the particularities of concurrent terminologies, Hawlett frames the issue claiming that community radio is best understood when looking at both its activities and objectives in context, which can occur either in separate or simultaneous manners. The author then names examples of goals that a station can work towards, such as being 'an alternative or addition to existing media' or a 'beneficial extension of civil society' (Hawlett 2009: 39).

The attention paid to community radio in the 1970s is not accidental. The decade coincides with the end of the 'long sixties', which is considered the longest cycle of protest of the modern era (Melucci 1980). Community radio, much like other alternative media, can be considered a form of contentious politics - deeply embedded in other activist movements. At a wider level, Carroll and Hackett acknowledge that 'the struggle within civil society to democratize communication seems to satisfy certain criteria for social movements' (2006: 99, original emphasis), before arguing that 'media activism problematizes standard conceptions of "success" in the social-movement literature' (2006: 100). The researchers outline this connection, explaining that both traditions in social movements theory - resource mobilization approach defended by Gamson and Tilly, and new social movements theory supported by Melucci and often grounded in Habermasian critical theory - provide valid theoretical frames to media activism. 
In terms of alternative media, Atton explains that, notwithstanding some theoretical variations, scholars mostly agree that both participation and control are crucial for the establishment of such enterprises in the context of new social movements (2002, 2015). In addition, Carpentier acknowledges that the democracy in community radio stations is predominantly based on the 'structural participation and horizontal decision-making of the radio organization, which are deemed crucial for the democratic functioning of these media organizations' (2011: 340).

In the case of the community-based radio stations that arose in Europe at the time, irrespective of their politically or non-politically inclined missions, the mission of each one was somehow similar: 'giving voice to the voiceless'. In fact, the idea of a third sector of radio, one beyond the commercial and public service radio typologies, envisioned community radio as a social movement itself (Anderson 2017; Lewis and Booth 1989; McCarthy and Zald 1977). Remarkably, the decade also marks the starting point of regulatory and legal frameworks that judicially recognize and validate the existence of such structures in a variety of European countries, such as the Scandinavian ones, the Netherlands, Germany and the United Kingdom (Coyer et al. 2011; Lewis and Booth 1989).

It is worth noting, however, that despite its prevalence in the literature as a focal point of the global view of the medium, the European history of community radio is embedded in a wider web of events and struggles spread across the world, which can be traced back to the early 1900s and located in virtually any continent (King 2017). As such, even though it is still a focal point for many advocacy stations (stations that place advocacy at the centre of their practice), one can hardly say that all community radio has struggle at the core of its practice in westernized countries. There might still be a hint of struggle as community stations battle the airwaves against the heavily formatted commercial ones, but in western societies, where free speech remains a fundamental doctrine, community radio is no longer a space of contentiousness as it once was. Assuredly, it is still carried out by many activist groups, but it is also made by students and local communities that may or may not have specific agendas, meaning that in many cases they are not politicized, nor are they fighting for their own legitimacy as a broadcasting group, as they have already found that ground. That is not to say, however, that the struggle for an alternative has ended. Both in democratic and in totalitarian societies, community radio still functions as an important tool of empowerment.

King's description of the present moment, a 'resurgence period of community radio' that started in the $1990 \mathrm{~s}$, notes that over the last (nearly) three decades, there have been substantial developments in community radio across the world, with stations opening in dozens of countries, as appropriate regulatory frameworks were instated locally (King 2017: 27.). King also reflects on how the accessibility and affordability of technical means and production equipment played an important 
role in such growth, but underscores the lack of legal frameworks enabling community radio broadcasting as the main obstacle to their operation nowadays (2017).

\section{Theoretical background on free software and open source}

Open-source software and communities have been extensively studied all around the world, particularly in the last twenty years, with a focus on their integration into everyday lives and their role in the development of new disciplines such as digital humanities and software studies. Beyond engineering and computer science, research in open source is still intrinsically connected to discourses related to coding (Manovich 2013; Stallman 2010) and its various iterations, and law (Lessig 2004; Rosen 2005).

Richard M. Stallman was the pioneer of the free software movement, being responsible for laying the very first stone of the endeavour, the GNU operating system. The story can be traced back to 1984, when Stallman started the project (DiBona et al. 1999; Raymond 2001; Stallman 2010). In an unprecedented move at the time, the foundations of this movement were set in philosophy more than on programming languages as Stallman's work derived from his own freedom manifest. Stallman argues that software should be free as it does not encompass an artistic or fruition purpose; instead it fills a practical function and, therefore, should be developed and made available in a manner that allows others to shape it and perfect it as they need. Stallman's four freedoms are then based on the users' perspective and what they are allowed to do with the software - 'Free software is a matter of the users' freedom to run, copy, distribute, study, change and improve the software' (2010:3).

Stallman's emphasis on forcing redistributed works to be kept equally as open as the original code worried other leaders devoted to the cause. In 1997, this group gathered to discuss how to get companies and organizations' interest back as the philosophy of the movement inaugurated by Stallman, and later continued by Free Software Foundation, was often seen as extreme (DiBona et al. 1999). This marked the beginning of the open-source view that stands today. For the supporters of this perspective, open source means making the code available for others, but also allowing them to reuse them in their desired manner, including redistributing derivative products under more restrictive terms (Raymond 2001).

The difference in motivation and the ideology behind each approach is illustrated through the different sets of licenses that each one accepts as their own. As Laurent (2004) points out, open-source software is software that has its source code made publicly available under a designated license; such license can be more or less permissive, but it allows the software holder to study, modify and redistribute new versions of the software (Laurent 2004). Licenses also regulate things such as patent grants and specific conditions for further product distribution, but the divergence between them means 
that not all licenses are compatible with each other as they can entail different types of permissions (Laurent 2004; Rosen 2005). For broader purposes, however, both parties agree that even though free software and open source are slightly conceptually distinct, they share essential characteristics, such as source code sharing, and their practicalities often intersect and overlap. The Free Software Foundation clarifies the matter, explaining that 'nearly all free software is open source, and nearly all open source software is free' (GNU.org n.d.); Stallman adds "Free software" and "open source" describe the same category of software, more or less, but say different things about the software, and about values' (2010: 23).

According to the open-source software business models, economical agents promote them by deploying open-source software so that businesses and economies can prosper since they foster the perfect conditions, increasing a country's market and saving on software licenses, usually paid to other countries. This line of thought also emphasizes the quality of open-source software and the longer life cycle for those systems and technology (Aparicio and Costa 2012; Damiani et al. 2015; Riehle 2010). Today, open source is prosperous, coexisting alongside proprietary software as a force of its own within the information and technology industry. As of November 2018, Github hosts more

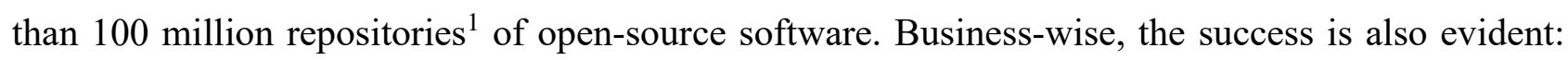
that same month, IBM closed a deal to acquire Red Hat Enterprises, an open source-only supported business, for approximately $\$ 34$ billion, in one of the most expensive business acquisitions to date.

In terms of open source, academics have paid close attention to the fundamental role of communities in the development of open-source projects, covering a variety of topics from community management and governance (O’Mahony 2007; O’Mahony and Ferraro 2007; Shah 2006), to their sustainability and the motivation behind a member's association with a given opensource community (Bitzer et al. 2007; Gamalielsson and Lundell 2014; Roberts et al. 2006). With a few exceptions, the study of the community within open-source development contexts remains 'codecentric', meaning that research is still mainly fixated on contributions to code rather than on wider understandings of the transactions and interactions happening between their members and across the encompassing structures (Rozas and Gilbert 2015). It seems to be clear, however, that the community is seen as the engine of the open-source machine, fuelling innovation and actively driving the gears of the technological revolution.

\section{The bridges towards community radio}

While software may appear as the most obvious link between both universes, community radio stations and open-source projects share characteristics far beyond the technical aspect, namely their reliance on what is mostly a volunteer community, leaning towards participatory governance. In 
addition, both need continuity: in the case of radio stations, the broadcast cannot stop; similarly, software needs to be updated frequently to keep up with the demands of users and security vulnerabilities.

From short-wave AM broadcasting to digital streaming, radio emerged as a transnational medium from its inception and has regained a new taste for it in the digital era. Over the last decade, research in radio studies has demonstrated a growing concern with various topics under this scope, such as aesthetics and formats, technology, places and identities, policies, archiving and memory, and more; community radio is a crucial part of this ever-growing field (Föllmer and Badenoch 2017; Mitchell and Lewis 2017). Similarly, largely potentiated by their digital nature, open-source communities operate in a transnational sphere, where country borders have limited or no influence over how their members interact or develop their sense of belonging (Djelic and Quack 2010). Plus, the freedom to use and share the software unlocks the usage of open-source software by consumers worldwide.

In terms of their collective aspect, it is worth noting that academics have also framed community radio and open source as de facto social movements (Anderson 2017; Holtgrewe and Werle 2001). It is arguable if either one fits in such categorization. According to Tarrow, social movements are bound by three key points: (1) a conflict against a clear opponent, (2) an identity and (3) a dense social network (2011). In this sense, it can be argued that radio stations, as media, potentiate the reinforcement of social networks, but the connection between both spheres is beyond this, falling under the scope of collective action, a concept defined by Melucci as 'the existence of a struggle between two actors for the appropriation and orientation of social values and resources, each of the actors being characterized by a specific solidarity' (1980: 202). Even though he disagrees with the view of the group as an irrational actor, Tarrow sees collective action as one of the fundamentals of contentious politics, which is the usage of a set of collective action techniques to create political change (2011). With such close yet distinct attributes, open source and community radio seemingly share the aspects of social movements, depending on the context.

Looking at the timeline of emergence and further development of studies in either subject, it comes as a striking coincidence that in 1997, two events marked major turning points in their scholarly development. The first is the establishment of the Radio Studies Network, a turning point in the establishment of radio studies as its own area of research (Lacey 2008). The second is the publication of Eric Raymond's 'The Cathedral and the Bazaar', an essay later turned into book, which led to the understanding of open software that prevails to this day (2001). In addition, most literature in both realms tends to focus on issues of practice, notwithstanding various reflections and theoretical frameworks that aim to tackle specific epistemological challenges in each sphere. 
The scope of this article and the initial stage towards imagining a possible new framework required that the team only focused on the empirical research on European stations. According to the International Telecommunication Union (2017), Europe is the continent with the highest percentage of population connected to the internet at home (84.2 per cent) and with the widest bandwidth per user (178kbit/per internet user) (International Telecommunication Union 2017). Beyond the number of connections, it is worth noting that these data obscure a 'digital divide' that spans across age groups, gender, social class and other demographic categories. As the planet becomes more connected, this separation becomes increasingly evident in the digital skills and literacy, rather than on the access to the online world (Ragnedda and Muschert 2013). The challenge posed by such imbalance is transnational - 'there will be fewer positive payoffs for people from less privileged backgrounds, which means that the Internet will reinforce or even increase existing social inequalities' (Zillien and Marr 2013: 67). For community radio, while researching South African stations, Bosch has found that 'technologies have impacted on the daily routines of community radio journalists who increasingly rely on the internet as a source of news' (2014: 29), acknowledging that the 'digital divide' prevented underprivileged audiences from engaging digitally with the stations.

\subsection{Technology}

As previously mentioned, the most immediate connection between open source and community radio is the use of open-source software to run the operation. From digital audio workstations to produce content to playout systems for broadcasting, from social media for interaction with audiences to 'listen again' functionalities that challenge the need for synchronicity between broadcasting and listening, software is a fundamental part of most radio stations nowadays (Dubber 2014; McLeish 2005) irrespective of their dimension and mission. Community radio stations have been pioneers in embracing technological advancements ahead of other stations as a way to increase their Hertzian-limited reach or to solve specific problems (Scifo 2015). Resonance FM in London, for instance, established itself as a webradio long before securing its broadcast license; Rádio Zero in Lisbon, Portugal, has used podcasts since 2006 as an alternative route to ensure the appropriate storage and preservation of the digital content that they produced, namely all the output produced with the exception of continuity broadcast (Costa 2008).

To further grasp the already-existing connections between spheres, exploratory interviews were conducted with some community station managers in the United Kingdom and in Portugal between 2017 and 2018. As Given suggests, this method has been widely used 'when studying relatively new domains' (2008: 906) - while neither community radio nor open source are new 
objects, their relationship is still mostly uncharted. The interviews were informal and took place both in-person and via e-mail, with the latter being used due to geographical constraints when necessary. Presential conversations followed an unstructured model, allowing the participants to articulate their views in greater depth. Due to the limitations of the medium, interviews led through e-mail were semi-structured.

Based at an engineering faculty, Rádio Zero stands out as an example of the connection between community radio and open source as their computers run on Linux-based operating system Ubuntu and the content production is done with Audacity. ${ }^{2}$ Members with advanced knowledge in programming are also encouraged to develop software to answer specific needs of the station - two of them have successfully argued such projects as their masters' theses (Costa 2008; Silva 2008). In exploratory interviews, members of the current interim managing team have expressed their desire to advance their GitHub-hosted Zero Labs initiative, a lab-type scheme for open-source software development.

Some other preparatory connections with UK-based and Ofcom-licensed community stations exposed how Soundart Radio, in Dartington, uses and advocates for the use of open-source software. They have mentioned that the station provides adequate radio training to their members in software such as Audacity and DJ-oriented Mixxx. ${ }^{3}$ Even though most of their computers run on Windows, they broadcast using BUTT ${ }^{4}$ (broadcast using this tool), an open-source tool. For Soundart managers, open-source software is in line with their station's philosophy of freedom, while allowing both newcomers and the station itself to keep costs to a minimum. Further west, a manager at Source FM in Cornwall confirmed the costs reasoning, claiming that this type of software tends to be free and highlighted the fact that it can also be adapted if needed. At that station, OSS is used for editing, postproduction, recording of the transmission and online streaming. On top of Audacity and BUTT, they mentioned LibreOffice ${ }^{5}$ as an OSS used daily.

These findings should not imply that all (or even a large part of) community radio stations in Europe are using open-source software. Many of them still lack the knowledgeable staff able to differentiate it from other software, let alone being able to code additional features or adjustments. As previously addressed, community radio stations exist under an extremely wide umbrella of motivations and formats, meaning that their realities will be just as various.

Beyond academia, UNESCO has carried out significant research on the impact that community radio stations can have in developing communities (Berrigan 1981), and in enabling and reinforcing freedom by creating participatory structures (Fraser and Estrada 2001); UNESCO has also advised on the use of free and open-source software in such stations (Rajshekharan and Nafala 2009). 
Slightly beyond the scope of community radio, but still in the realm of collaborative alternative media, Atton accounted how using 'open source software bypasses the need for an editor or webmaster' at Indymedia (2003: 8), pointing towards the potential for open-source technology to enable participatory practices in media content production.

\subsection{Content}

If the broadcast is the core of a radio station's operation, the content is the core of the broadcast. It is what makes each radio station alive, taking up almost as many forms as human interactions. In fact, a significant portion of the arguments around what radio is or what it is not focus on content. Along with words, sounds and silence, Crisell identified music as one of the signs of radio. Music, he contends, occupies a specific place in radio as opposed to 'sounds' because of its aural nature and 'because in being largely free of signification it allows us to listen without making strenuous efforts to imagine what is being referred to, but to assimilate it, if we wish, to our own thoughts and moods' (1994: 49); he continues by claiming that music is the most used content in radio.

Beyond the complexity of programming strategies typically found in music-oriented stations, music in community radio may pose a particular challenge as playing it on air may come at an extra cost because of the need to secure the appropriate licenses with rights holders. For reference values, in 2018, United Kingdom's PPL and PRS for Music Joint Licence for Community Radio accounts for an annual cost of at least $£ 890 /$ year for a station broadcasting on an FM/AM license plus an online Internet simulcast that supports up to 200 connections at once ('Community radio [AM/FM only] PPL' n.d.); Notes of guidance for community radio licence applicants and license 2010). Such values can be significantly higher for increased simulcast connections and DAB broadcasting.

Although it may not be suitable for every station, alternative content-licensing models, such as Creative Commons (CC), may be considered valuable alternatives to the current all rights reserved model. Creative Commons are free user-focused licenses that allow sharing and usage of creative work such as text, images and music (Lessig 2004). They abide by specific terms chosen by the author, such as non-commercial protection or the requirement to share derivative works under the same conditions. Finally, as the licenses are legally recognized in various countries, they provide a transnational safe harbour for creators to use them and even build upon those works. CC licenses draw directly from Stallman's copyleft vision for free software. In his words, it 'Copyleft is a general method for making a program (or other work) free and requiring all modified and extended versions of the program to be free as well' (2010: 127). Although there is very limited research in this topic, 
Creative Commons licenses have been used by community radio stations and other participatory media to produce and publish (at least part of) their work (Bergés Saura 2012; Ó Baoill 2014).

Even beyond the scope of community radio, the usage of freely licensed music remains largely undocumented and sparse among audio professionals (Font et al. 2016). Investigations conducted by the Audio Commons project explain that there is a 'lack of a shared culture and understanding within the creative industries of open content and its potential use' (Font et al. 2016: 2); adding that to the technical challenge of dispersed databases and resources may clarify why such a substitute remains basically uncharted.

The usage of Creative Commons can potentially have a double impact: on top of lowering costs on the production, they also provide an unequivocal way to share content online - something that may be particularly useful for shows or radio stations catering to specific audiences, such as displaced communities, like refugees or diasporas, and to certain niches of interest that may not be anchored in locality.

\subsection{Community}

Gacek et al.'s identification of mutual features across open-source projects matches almost perfectly the features common to community radio environments (2002). The research team classified two sets of features to create a 'tick-list' that would provide an assessment framework to determine whether a project is open source or not beyond their self-statement as such. The first set focused on characteristics found in every successful OSS project analysed; the second one examined characteristics for which implementation could vary. In Table 1, there is an enumeration of the features identified on the first set, with their application in community contexts.

\begin{tabular}{|l|l|l|}
\hline OSS features & \multicolumn{1}{|c|}{ Application in CR } & \multicolumn{1}{|c|}{ Cases/references } \\
\hline Community & $\begin{array}{l}\text { Community is well defined, active and engaged in the } \\
\text { production efforts and decision-making at the radio station }\end{array}$ & $\begin{array}{l}\text { (Carpentier 2011; } \\
\text { Chignell 2009; Fogg } \\
\text { et al. 2005; Lister et } \\
\text { al. 2010) }\end{array}$ \\
\hline Motivation & $\begin{array}{l}\text { Contributor types may vary, but as the vast majority work } \\
\text { voluntarily, motivation is crucial for the sustainability of the } \\
\text { broadcast }\end{array}$ & Vuuren 2002) \\
\hline $\begin{array}{l}\text { Developer's } \\
\text { profile }\end{array}$ & $\begin{array}{l}\text { 'All open source developers are users, but not all users are } \\
\text { developers' - similarly, all CR producers are part of the } \\
\text { audience, but not all members of the audience act as content } \\
\text { producers }\end{array}$ & (King 2015) \\
\hline
\end{tabular}




\begin{tabular}{|l|l|l|}
\hline OSS features & \multicolumn{1}{|c|}{ Application in CR } & \multicolumn{1}{|c|}{ Cases/references } \\
\hline $\begin{array}{l}\text { Process of } \\
\text { accepting } \\
\text { submissions }\end{array}$ & $\begin{array}{l}\text { CR must be open to submissions; onset processes can differ } \\
\text { greatly and even limit the type of submissions; i.e. a station } \\
\text { might be open to submissions for new shows but limit the } \\
\text { decision-making power of members }\end{array}$ & $\begin{array}{l}\text { Fraser and Estrada } \\
2001)\end{array}$ \\
\hline $\begin{array}{l}\text { Development } \\
\text { improvement } \\
\text { cycles }\end{array}$ & $\begin{array}{l}\text { 'Breakthrough' and 'continuous improvement' cycles of } \\
\text { impetus: i.e. premiering a new programming schedule is a } \\
\text { breakthrough, improving shows over time replicates the } \\
\text { continuity cycle found in software }\end{array}$ & $\begin{array}{l}\text { (Keith 2010; Lister et } \\
\text { al. 2010) }\end{array}$ \\
\hline Modularity & $\begin{array}{l}\text { The radio operation is split across distinct activities, such as } \\
\text { content production, tech support, administrative board or } \\
\text { music team, and they often operate separately }\end{array}$ & (Lister et al. 2010) \\
\hline
\end{tabular}

Table 1: Features of successful open-source projects adapted to community radio contexts.

Focusing on the community sphere and examining another systematization model of the community in OSS development, O'Mahony articulated the idea of community management as a governance model for such projects, identifying its features and providing ways of evaluating each one (2007). To do so, she studied 'four large, mature OSS communities (the Apache, Debian, GNOME, and Linux Standards Base communities) from 2000 to 2002' (O'Mahony 2007: 144). The scholar pinpointed five features of community-managed governance model OSS: (1) independence, (2) pluralism, (3) representation, (4) decentralized decision-making and (5) autonomous participation (O’Mahony 2007: 149). This framework can also be placed under Carpentier's maximalist democratic participation model, a prevalent approach in community radio structures (2011). This model attempts to maximize partaking with a layered approach, which joins micro and macro levels, emphases on diversity, and balances representation and participation (Carpentier 2011: 17).

Similarly, open-source community-managed projects tend to gravitate towards more open and democratic structures, often organized horizontally. 


\section{Conclusions and future work}

This study's main objective was to lay the ground work towards a theoretical framework for the sustainability of community radio stations based on the open-source movement. By tracing similar concepts and views across the literature in both realms, we were able interconnect the two areas. Three main axes were successfully identified - technology, content and community - while also mapping existing research in both fields and current gaps. This process introduced various sets of questions for examination. In terms of content, further investigation could look into the following: (1) how open practices influence content production workflows; (2) how copyleft licenses, such as Creative Commons, impact content distribution live, online and offline; and (3) the reasons behind a station's choice for open content practices. In terms of technology, some of the lines of research could be as follows: (1) how open-source technology can be used for radio production and airplay; (2) how using open-source software can potentiate participatory structures; and (3) how the transferred ownership of the software, and the possibility of modification, affects the station. Finally, communitywise, scholars could scrutinize (1) how open-source models of governance and open practices can fit in a radio station structure; (2) how open-source practices can be embedded in community management and subsequent effects; and (3) how open-source practices and software powers members access, for instance.

At all levels, Carpentier's AIP model, which stands for Access, Interaction, Participation, could provide valuable insights. Three concepts crucial to a community involvement analysis, alongside the differentiation as suggested by the author, offer a deeper understanding of how the members' activity unfolds and impacts the communication processes. The model organizes the different levels under which these three concepts operate - content, technology, people (here, the community) and organization (here, the radio station) - in association with the two dimensions of the communicational process: production and reception. Case studies of community radio stations that already use open-source methods and frameworks could be investigated; it is crucial that such an examination is built upon various cases studies since - as previously mentioned - community radio stations follow different traditions depending on the country of origin and abide by different regulations. Diversity in case studies is critical to understanding how such stations can operate through open source, despite their different identities and specificities.

Finally, the main contributions are twofold: on top of this initial conceptual contextualization that can help other researchers conduct more in-depth studies on this matter, a second contribution translates into the practical implications of this study. By unlocking such connections, it is hoped that community radio stations can already take steps further into their longevity by implementing the principles of open source, and related iterations, such as Creative Commons licenses. 


\section{References}

Ala-Fossi, Marko; Lax, Stephen; O’Neill, Brian; Jauert, Per and Shaw, Helen (2008), 'DAB: The future of radio? The development of digital radio in four European countries', Media, Culture \& Society, 30:2, pp. 151-66.

Anderson, Heather (2017), 'The institutionalization of community radio as a social movement organization: 4ZZZ as a radical case study', Journal of Radio \& Audio Media, 24:2, pp. 251-69.

Aparicio, Manuela and Costa, Carlos. J. (2012), 'Macroeconomics leverage trough open source', in Manuela Aparicio and Carlos J. Costa (eds) Proceedings of the Workshop on Open Source and Design of Communication - OSDOC ’12, Lisboa: ACM Press, pp. 19-24.

Atton, Chris (2002), Alternative Media, London; Thousand Oaks, CA: SAGE.

(2003), 'Reshaping social movement media for a new millennium', Social Movement Studies, 2:1, pp. 3-15.

(ed.) (2015), The Routledge Companion to Alternative and Community Media, London and New York: Routledge and Taylor \& Francis Group.

Berrigan, Frances J. (1981), Community Communications: The Role of Community Media in Development by Frances J. Berrigan, Paris: UNESCO.

Bitzer, Jürgen, Schrettl, Wolfram and Schröder, Philipp J. H. (2007), 'Intrinsic motivation in open source software development’, Journal of Comparative Economics, 35:1, pp. 160-69.

Bosch, Tanja (2014), 'Social media and community radio journalism in South Africa', Digital Journalism, 2:1, pp. 29-43.

Carpentier, Nico (2011), Media and Participation: A Site of Ideological-Democratic Struggle, Bristol: Intellect.

(2015), 'Differentiating between access, interaction and participation', Conjunctions.

Transdisciplinary Journal of Cultural Participation, 2:2, pp. 7-28.

Carroll, William K. and Hackett, Robert A. (2006), 'Democratic media activism through the lens of social movement theory', Media, Culture \& Society, 28:1, pp. 83-104.

Chignell, Hugh (2009), Key Concepts in Radio Studies, London: Thousand Oaks, CA: SAGE.

Coyer, Kate, Dowmunt, Tony, and Fountain, Alan (2011), The Alternative Media Handbook, Hoboken: Taylor and Francis. 
Costa, Daniel António Quaresma (2008), 'Radia Store - Armazenamento e Preservação de Programas de Rádio’, MA dissertation, Lisbon: IST - Instituto Superior Técnico.

Crisell, Andrew (1994), Understanding Radio, $2^{\text {nd }}$ ed., London and New York: Routledge.

Damiani, Ernesto, Frati, Fulvio, Riehle, Dirk and Wasserman, Anthony I. (eds) (2015), Open Source Systems: Adoption and Impact, $1^{\text {st }}$ ed., New York, NY: Springer Berlin Heidelberg.

Deiss, Richard (2002), Radio Broadcasting Market, Luxembourg: Eurostat

DiBona, Chris, Ockman, Sam and Stone, Mark (eds) (1999), Open Sources: Voices from the Open Source Revolution, Sebastopol: O’Reilly.

Djelic, Marie-Laure. And Quack, Sigrid (eds) (2010), Transnational Communities: Shaping Global Economic Governance, Cambridge: Cambridge University Press.

Dubber, Andrew (2014), Radio in the Digital Age, Cambridge: Polity.

Eurostat (2011), Cultural Statistics, Luxembourg: Publications Office of the European Union.

Fogg, Ally, Korbel, Phil and Brooks, Cathy (2005), Community Radio Toolkit, Manchester: Radio Regen.

Föllmer, Golo and Badenoch, Alexander (eds) (2017), Transnationalizing Radio Research: New Approaches to an Old Medium, Bielefeld: transcript.

Font, Frederic; Brookes, Tim; Fazekas, George; Guerber, Martin; La Burthe, Amaury; Plans, David; Plumbley, Mark D.; Shaashua, Meir; Wang, Wenwu and Serra, Xavier (2016), 'Audio commons: Bringing creative commons audio content to the creative industries', Audio Engineering Society Conference: $61^{\text {st }}$ International Conference: Audio for Games, London, 2016 February.

Fraser, Colin and Estrada, Sonia Restrepo (2001), Community Radio Handbook, Paris: UNESCO.

Gamalielsson, Jonas and Lundell, Björn (2014), 'Sustainability of open source software communities beyond a fork: How and why has the LibreOffice project evolved?', Journal of Systems and Software, 89, pp. 128-45.

Given, Lisa M. (ed.) (2008), The Sage Encyclopedia of Qualitative Research Methods, Los Angeles, CA: Sage Publications.

Gnu.Org (2018) ‘What is free software?’, Gnu.org, https://www.gnu.org/philosophy/freesw.en.html. Accessed 24 Nov 2018. 
Hawlett, Laurie (2009), ‘The space between: Making room for community radio’, in J. Gordon (ed) Notions of Community: A Collection of Community Media Debates and Dilemmas, Switzerland: Peter Lang.

Holtgrewe, Ursula and Werle, Raymund (2001), 'Open source software between business strategy and social movement', Science Studies, 14:2, pp. 43-65.

Hussain, Faheem and Tongia, Rahul (2007), 'Community radio for development in South Asia: A sustainability study', in 2007 International Conference on Information and Communication Technologies and Development, Bangalore: IEEE. Pp. 1-13, https://doi.org/10.1109/ICTD.2007.4937412.

International Telecommunication Union (2017), ICT Facts and Figures 2017, Switzerland: International Telecommunication Union, https://www.itu.int/en/ITUD/Statistics/Documents/facts/ICTFactsFigures2017.pdf.

Jallov, Birgitte. (2001), Creating Sustainable Community Radio Stations - A Major Challenge!, Mozambique: UNESCO, http://www.mediamoz.com/CR/.

Keith, Michael C. (2010), The Radio Station: Broadcast, Satellite \& Internet, Oxford: Focal Press.

King, Gretchen (2015), 'Hearing community radio listeners: A storytelling approach for community media audience research', Participations, Journal of Audience and Reception Studies, 12:2, pp. 121-46.

(2017), 'History of struggle: The global story of community broadcasting practices, or a Brief history of community radio', Westminster Papers in Communication and Culture, 12:2, p. 18.

Kogawa, Tetsuo (1993), 'Free radio in Japan: The Mini FM boom', in N. Strauss and D. Mandl (eds), Radiotext€, New York: Semiot€(e), pp. 90-96.

Lacey, Kate (2008), 'Ten years of radio studies: The very idea', International Studies in Broadcast and Audio Media, 6:1, pp. 21-33.

Laurent, Andrew M. St. (2004), Understanding Open Source and Free Software Licensing: Guide to Navigating Licensing Issues in Existing \& New Software, Sebastopol: O’Reilly Media

Lessig, Lawrence (2004), Free Culture: how big media uses technology and the law to lock down culture and control creativity, New York: The Penguin Press.

Lewis, Peter M. and Booth, Jerry (1989), The Invisible Medium: Public, Commercial and Community Radio, London: Macmillan Education UK. 
Lister, Brian; Mitchell, Caroline and O’Shea, Tony (2010), Managing Radio (ed. B. Lister), Sedgefield: Sound Concepts, http://www.soundconcepts.ltd.uk/managingradio/Managing Radio v2.pdf.

Manovich, Lev (2013) Software Takes Command, New York: Bloomsbury Academic.

McLeish, Robert (2005), Radio Production, $5^{\text {th }}$ ed., Oxford: Focal Press.

Melucci, Alberto (1980), 'The new social movements: A theoretical approach', Social Science Information, 19:2, pp. 199-226.

Milan, Stefania (2008), 'What makes you happy? Insights into feelings and muses of community radio’, Westminster Papers in Communication and Culture, 5:1, pp. 25-43.

Mitchell, Caroline. and Lewis, Peter. M. (2017), 'Community radio and transnational identities', in G. Föllmer and A. Badenoch (eds), Transnationalizing Radio Research: New Approaches to an Old Medium, Bielefeld: transcript, pp. 33-46.

Ofcom (2010), 'Notes of guidance for community radio licence applicants and license’

Ó Baoill, Andrew. 2014. 'Copyright, Community Radio, and Change: How the U.S. Community Radio Sector Is Negotiating Changing Copyright Rules and the Rollout of Digital Distribution'. Journal of Radio \& Audio Media 21(1), 163-76.

O’Mahony, Siobhán (2007), 'The governance of open source initiatives: what does it mean to be community managed?’, Journal of Management \& Governance, 11:2, pp. 139-50.

O’Mahony, Siobhán and Ferraro, Fabrizio (2007), 'The emergence of governance in an open source community’, Academy of Management Journal, 50:5, pp. 1079-106.

PPL (2018), 'Community radio (AM/FM only) - PPL', PPL UK, http://www.ppluk.com/I-PlayMusic/Radio-Broadcasting/Radio-types/Community-radio/. Accessed 3 December 2018.

Raboy, Marc (1993), 'Radio as an emancipatory practice', in N. Strauss, and D. Mandl (eds), Radiotext(e), New York: Semiotext(e), pp. 129-34.

Ragnedda, Massimo and Muschert, Glenn W. (eds) (2013), The Digital Divide: The Internet and Social Inequality in International Perspective, London and New York: Routledge and Taylor \& Francis Group.

Rajshekharan, K. and Nafala, K. M. (2009), Digital Archiving of Audio Content Using WINISIS and Greenstone Software: A Manual for Community Radio Managers (ed. B. K. Sen), New Delhi: UNESCO. 
Raymond, Eric. S. (2001), The Cathedral \& the Bazaar: Musings on Linux and Open Source by an Accidental Revolutionary, Sebastopol: O’Reilly Media.

Riehle, Dirk (2010), 'The economic case for open source 'foundations', Computer, 43:1, pp. 86-90.

Roberts, Jeffrey A., Hann, Il-Horn and Slaughter, Sandra A. (2006), 'Understanding the motivations, participation, and performance of open source software developers: A longitudinal study of the Apache projects’, Management Science, 52:7, pp. 984-99.

Rosen, Lawrence (2005), Open Source Licensing: Software Freedom and Intellectual Property Law, New Jersey: Prentice Hall PTR

Rozas, David and Gilbert, Nigel (2015), 'Talk is silver, code is gold? Contribution beyond source code in Free/Libre Open Source Software communities' in CRESS Working Papers, Surrey: Centre for Research in Social Simulation.

Saura, Laura Bergés. 2012. 'Spain: An Information Society Without Traditional Offline Community Media?’ Journal of Radio \& Audio Media 19(2), 134-51.

Scifo, Salvatore. (2015), 'Technology, empowerment and community radio’, Revista_Mídia_e_Cotidiano, 7:7,pp. 84-111.

Shah, Sonali K. (2006), 'Motivation, governance, and the viability of hybrid forms in open source software development', Management Science, 52:7, pp. 1000-14.

Silva, Daniel Enrique Zacarias (2008), 'Radia Source - Sistema de Informação para Gestão de Processos de uma Estação de Rádio’, MA dissertation, Lisbon: IST - Instituto Superior Técnico.

Stallman, Richard. M. (2010), Free Software, Free Society - Selected Essays of Richard M. Stallman (ed. J. Gay), 2nd ed., Boston: Free Software Foundation, http://www.gnu.org/doc/fsfs-ii2.pdf.

Tarrow, Sidney. (2011), Power in Movement: Social Movements and Contentious Politics, 3rd ed., Cambridge: Cambridge University Press.

Van Vuuren, Kitty (2002), 'Beyond the studio: A case study of community radio and social capital', Media International Australia Incorporating Culture and Policy, 103:1, pp. 94-108.

Zillien, Nicole and Marr, Mirko (2013), 'The digital divide in Europe’, in M. Ragnedda, and G. W. Muschert (eds), The Digital Divide: The Internet and Social Inequality in International Perspective, London and New York: Routledge and Taylor \& Francis Group. pp. 55-66. 


\section{Contributor details}

Rute Correia is a Ph.D. candidate in communication at ISCTE - Instituto Universitário de Lisboa, researching how open source can be integrated in community radio stations in terms of content, technology and community to provide a sustainable broadcast practice. She has a Master of Arts in radio from the University of Sunderland, where she developed radio content for syndication on community radio stations. The project won her the Silver Innovation Award of the Year at the Community Radio Awards 2016. She has more than a decade of experience as a broadcaster, having produced and hosted content for radio stations in Portugal, Spain and the United Kingdom; her work spans commercial, public service and community radio.

Jorge Vieira is a visiting assistant professor in the Department of Sociology of the School of Sociology and Public Policies at ISCTE - Instituto Universitário de Lisboa. He holds a Ph.D. in sociology and a master's in communication, culture and information technology from ISCTE-IUL. He teaches and tutors in the master's programmes of communication, culture and information technologies; entrepreneurship and culture studies, and in the graduation in sociology and in the Ph.D. in communication sciences. In addition, he develops research at the Center for Research and Studies of Sociology - CIES-IUL and OberCom - Observatório da Comunicação. He received the Paquete de Oliveira Award - National Excellence Award for Ph.D. theses at Portuguese Universities in 2017.

Manuela Aparicio is an integrated researcher and assistant professor at the Information Sciences, Technologies and Architecture Research Center (ISTAR-IUL), University Insitute of Lisbon, Portugal (ISCTE-IUL), and associate researcher at MagIC, a Portugal-based research centre focusing on harnessing information to improve organizations and society. She is also an assistant professor at Universidade Nova de Lisboa. Her research interests include the evaluation of information systems' effectiveness, especially with respect to the implementation and use of information technology in education. Aparicio is also interested in e-learning systems success research. She conducted a bibliometric study on e-learning evolution concepts and proposed two different business models for massive online open courses (MOOCs). Her work has appeared in the Journal of Educational Technology \& Society, Internet and Higher Education, Computers in Human Behavior, Information and Management and others. Aparicio is chair of the European ACM SIGDOC Chapter (EuroSIGDOC). 
Contacts:

Rute Correia and Jorge Vieira, Instituto Universitário de Lisboa (ISCTE-IUL), Centro de Investigação e Estudos de Sociologia (CIES-IUL), Lisboa, Portugal

Manuela Aparicio, Instituto Universitário de Lisboa (ISCTE-IUL) ISTAR-IUL

Information Management School (Nova IMS), Universidade Nova de Lisboa, Portugal

E-mail: Ana_Rute_Correia@iscte-iul.pt

ORCID: https://orcid.org/0000-0003-3875-8215

Address: Centro de Investigação e Estudos de Sociologia (CIES-IUL)

Av. das Forças Armadas, Edifício I, Sala 2W6d

1649-026 Lisboa, Portugal

E-mail: Jorge Vieira@iscte-iul.pt

ORCID: http://orcid.org/0000-0002-1130-3731

Address: Escola de Sociologia e Políticas Públicas

Av. das Forças Armadas, Edifício II, Gabinete D325

1649-026 Lisboa, Portugal

E-mail: manuela.aparicio@novaims.unl.pt

ORCID: http://orcid.org/0000-0003-4261-0344

ISTAR-IUL

MagIC

Nova IMS, Campus de Campolide Universidade de Nova de Lisboa, 1070-312 Lisboa, Portugal

Notes

1 https://github.com/open-source - GitHub is an online software development platform that allows developers to code in a collaborative manner, while archiving both the code and its changes, acting as a version control system.

${ }^{2}$ https://www.audacityteam.org/ - Audacity is a free and open-source digital audio workstation. 3 https://www.mixxx.org/ - Mixxx is a free and open-source DJ software.

4 https://danielnoethen.de/ - BUTT (broadcast using this tool) is a free and open-source tool for online streaming developed by Daniel Nöthen.

${ }^{5}$ https://www.libreoffice.org/ - LibreOffice is a free and open-source office-suite software. 